\title{
reviews
}

\section{Mental Health Law: Policy and Practice}

Peter Bartlett \& Ralph Sandland. London: Blackstone Press. 2000. 494 pp. f24.95.

ISBN: 1-85431-941-8 pb

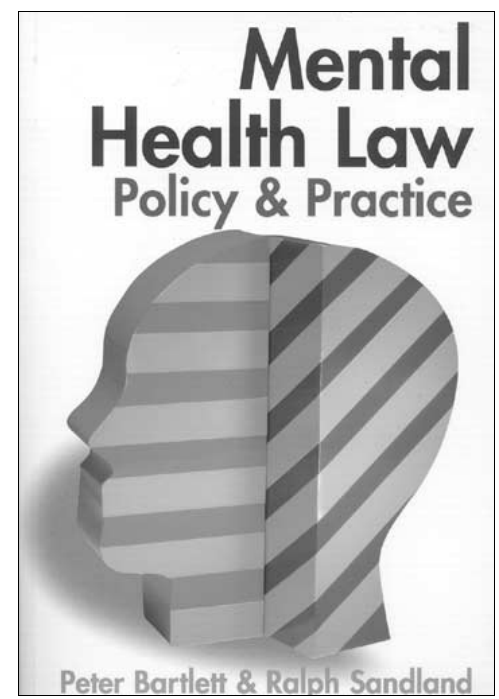

As the authors acknowledge at p. ix in their preface, there is no shortage of books on aspects of mental health law; they cite, for example, Eldergill's magisterial work on mental health review tribunals (MHRTs), Richard Jones' comprehensive Mental Health Act Manual and Brenda Hoggett's (The Hon. Mrs Justice Hale's) academic approach to mental health law in its various aspects. So, what, you may ask, do two academic lawyers bring that's new to the topic? Well, it depends on what you're looking for. Their stance is predominantly socio-legal; that is, they place discussion of past and current law and practice within sociocultural parameters. In essence, an examination of medicalism $v$. legalism, and on the whole they succeed. This is a substantial tome and not to be read from cover to cover. Its greatest use is as a source of well-informed reference. Those who teach mental health law and practice will find it very useful as it is well referenced and upto-date with its legal case citations. Psychiatrists may find some of the authors' allegiances to the works of Foucault and others not entirely to their liking, but they should overcome their prejudices. As a lay member of a MHRT for many years, I was particularly interested in their discussion and criticism of the system. I must confess I sometimes feel that those who criticise our practice might make their criticism more measured (and therefore more cogent) if they had actually sat on MHRTs and thus had some experience of the problems involved in reconciling patient need against public safety. Having said that, I did not find anything in the book that made my hackles rise unduly.

This is not to say that the book is free of error. Some examples follow. At p. 152 (line 5) there is a serious 'typo' - the word psychotic appears instead of psychopathic; on p. 154 (last line) the authors repeat the frequently found error that Section 136 of the 1983 Act refers to a public place; it doesn't, it refers to a place to which the public have access (not quite the same thing) and at p. 257 the once titled Aarvold Board is now more correctly cited as the Home Secretary's Advisory Board on Restricted Patients. It is also something of an exaggeration to refer to the poisoner Graham Young as a mass poisoner. Dennis Nilsen's name is misspelt, and at p. 260 the author's short statement as to the time an offender patient is likely to remain under conditional discharge supervision is confused. At p. 273 I wish it was the case that tribunals sit "in a committee room in the hospital" - if the authors visited a range of hospitals they would find a very different picture indeed one of their own local district general hospitals would readily confirm my observations. Finally, at p. 323, the authors assert that the case of Clunis was the first in a long line of homicide inquiries. Not so, the Sharon Campbell report, published in 1988, predated Clunis by some time.

Despite the above quibbles this book deals usefully with a wide range of mental health law and practice, including an extended discussion of the vexed question of mental incapacity. Thus, there is something for everyone. However, don't read it if you are expecting a non-drugabusing quick fix!

Professor Herschel Prins Midlands Centre for Criminology and Criminal Justice, University of Loughborough, Leicestershire LE11 3TU

\section{The Butterfly and the Serpent. Essays in Psychiatry, Race and Religion}

By Roland Littlewood. London: Free Association Books. 1998. 334 pp. ISBN: 1-85343-400-0 pb.

Roland Littlewood is Professor of Anthropology and Psychiatry at University College London, qualified in both subjects and particularly interested in exploring how the methods and traditions of anthropology can illuminate the subject matter of psychiatry. This book is a reprinted collection of 15 publications from 1980 to 1996, including important papers originally published jointly with Maurice Lipsedge and Simon Dein.
Littlewood and Lipsedge's important book, Aliens and Alienists, appeared in 1982 and has had a major influence on understanding in this difficult field.

It seems to this reviewer that anthropology is characterised by field work and the publication of careful accounts of it in terms of what might loosely be called the belief systems and social structures of the people studied. The descriptions of field work in this book make riveting reading; both of Littlewood's own work in Trinidad, and of his joint studies with Dein of an orthodox Jewish community in North London. In Trinidad, Littlewood lived for more than a year with a group led by a thyrotoxic woman with a set of beliefs in the religious domain that many people would regard as indicating madness. The group insisted upon nakedness for theological reasons. The report suggests an image of Littlewood having to join the group in order to conduct present state examination interviews with members.

Equally readable is the account (emerging from joint work with Simon Dein) of the societal habits of the ultra-orthodox Jewish community in North London, which builds on an early case report by Littlewood, giving a detailed account of a patient whose extremely unusual behaviour yielded to analysis in terms of knowledge of the rationale of the group's beliefs.

Littlewood loves theorising. He does it in an extremely scholarly and learned way and, apparently like other anthropologists, keeps referring to psychoanalysis as a sort of default comparator. This seems (to this reviewer) to be a pity, even though some manifestations of psychoanalysis have much to say about symbols (of great interest in anthropology), and the anthropological approach might well leave behind psychoanalytical theories. The theoretical part of the book is not an easy

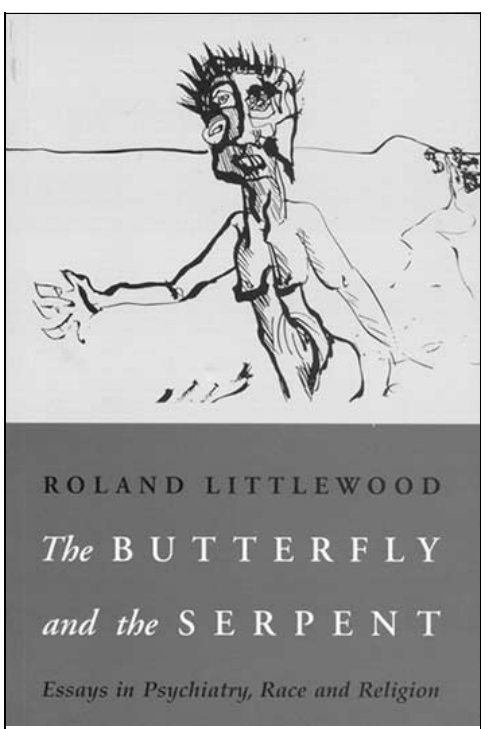


read and many will find that they need to read sentences more than once and to compile a lexicon of the jargon, which is no doubt necessary in this, as in other disciplines.

J. P. Watson Guy's Hospital, London SE1 9RT

\section{Child Sexual Abuse. Informing Practice from Research}

by D. P. H. Jones \& P. Ramchandani. Oxon: Radcliffe Medical Press. 119 pp. ISBN: 1-85775-362-3.

83

CHILD SEXUAL ABUSE

INFORMING PRACTICE From RESEARCH

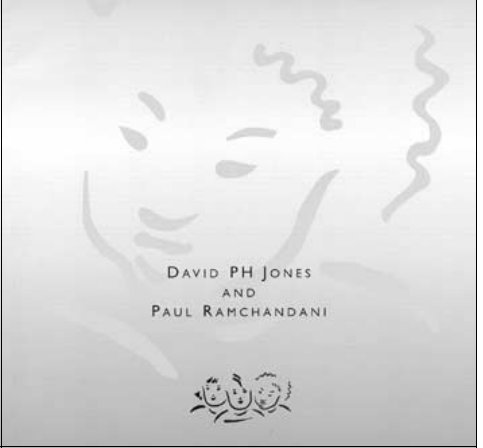

David Jones is a master of the review vignette and his skills emerge again in this important volume on informing practice from research. His qualitative analytical skills were notable in his joint book with McQuiston in 1986, Interviewing the Sexually Abused Child, which preceded the Cleveland Inquiry. He made a similar signal contribution to Child Sexual Abuse - The Principles of Good Practice, which underpinned parts of the Report of The Inquiry into Child Sex Abuse in Cleveland. These skills continue to be exemplified in his editorials for Child Abuse and Neglect. Over the years David Jones' technique has become more sophisticated and his editorials constitute essential reading for those in the field. His coauthor, Paul Ramchandani, has rapidly learnt those skills that have been applied to the task in hand. The net result is that this current volume will constitute a milestone in advances of knowledge and clinical practice in this subject.

The volume is not intended as a definitive comprehensive account, but rather the authors have explored options and selected themes that they considered to be of major significance. It is a model of clarity. Each chapter is introduced by a list of the main questions to be addressed. This is followed by brief accounts of the relevant findings and their evidence base. The authors deliberately avoid cumbersome detail but rather invite the reader to consider the original articles to ascertain for themselves whether or not they would place a similar weight on the evidence as given by the authors in the comments section. An invaluable contribution is the implications on practice section at the end of each chapter.

One is carried comfortably through nine themes - background factors; associated problems for the sexually abused child; referral and early planning; investigation and initial assessment; the Child Protection Conference; comprehensive assessment and planning; implementation, review and de-registration; psychological treatments; and measuring outcome.

It is a deceptively small book because it is so packed with clinically significant information. For the practitioner in the field it is a compulsive and quick read, but not too quick as one is likely to miss many gems. For me, one strength is its willingness to re-examine the many clinical notions, and even some long-standing myths that have emerged over the past decades and have been elevated over time into clinical ideology without any attempt to ascertain if they have a sound evidence-base, or at least face validity. Some readers will not necessarily wish to place the same weight on the evidence as that given by the authors, but when disagreeing they would be wise to provide evidence for the disagreement.

The volume is modern and up-to-date, but like all work in this field some of the notions and emergent guidelines will change with time. Nevertheless, it should be in the library of every social services department and constitute obligatory reading for those working in the field primarily social workers, mental health professionals and paediatricians - also those working in family law.

Israel Kolvin Bowlby Professor (Emeritus) Tavistock Centre, London

\section{Effective Ways of Working with Children and their Families}

Edited by Malcolm Hill. London: Jessica Kingsley Publishers. 1999. 304 pp. f15.95. ISBN: 1-85302619-0.

Children's issues have increasingly made the headlines, be that to do with child abuse, teenage crime, bullying or drug taking and overdosing. More recently children have also found a place on government agendas, particularly since the UK ratified the UN Convention on the Rights of the Child in 1991. However, the main responsibilities for children's welfare and development lie with their families, supported by a range of social, education and health services. Professionals working in these services have not only a social care role in relation to children and their families, but also a social control role Interventions therefore range from support to specific treatment to legal action, including removal of a child from the parental home. This book reviews the state of knowledge about the effectiveness of various forms of interventions with respect to children and their families. It covers a wide spectrum of services and approaches and its contributors are drawn from social work, psychiatry, psychology, education and family mediation. Most contributions have a strong research base, discussing the types of evidence available, noting limitations and pinpointing key findings relevant to practitioners.

The first part of the book deals with more general approaches, such as working with social networks, community-based interventions, family mediation and educational services for children with emotional and behavioural difficulties. A well-written chapter on family therapy reviews the evidence for its efficacy by examining various different outcome studies and concludes that there is strong support for the efficacy of family therapy and parent management-training in the treatment of general child conduct disorder, child aggression, eating disorders and global family problems. The second part of the book concentrates on particular kinds of children, such as working with fostered children and their families, children in residential care and therapeutic work with sexually abused children.

This is an impressive book, bringing together many different findings and data. I recommend it for all professionals working with children, families and the larger system.

K. Eia Asen Consultant Child and Adolescent Psychiatrist, Marlborough Family Service, 38 Marlborough Place, London NW8 OPJ

\section{Books received}

Quality Assurance. A Pathway to Excellence. D. N. T. Sale. Basingstoke \& London: Macmillan Press. 2000. 320 pp. f17.99. ISBN 0-333-74992-8 pb.

Guide to Assessment Scales in Schizophrenia. J. P. McEvoy. London: Science Press Ltd. 2000. 82 pp. £11.95. ISBN 185873-399-5 pb.

Maudsley Discussion Paper No. 9. Adoption as a Placement Choice: Arguments and Evidence. A. Rushton. London: King's College London. 2000. 22 pp. £4.00.

Growing Up Severely Autistic. They Call Me Gabriel. K. Rankin. London: Jessica Kingsley Publishers. 208 pp. £12.95. ISBN 1-85302-891-6 pb.

Coroners' Courts. A Guide to Law and Practice. C. Dorries. Chichester: John Wiley \& Sons. 385 pp. f34.95. 1-84174147-7 hb. 